\title{
Improved Application Technique in Potato Cultivation
}

\author{
Edward Irla ${ }^{a \star}$, Thomas Anken ${ }^{\mathrm{a}}$, Heinz Krebs ${ }^{\mathrm{b}}$, and Jacob Rüegg ${ }^{\mathrm{c}}$
}

\begin{abstract}
In particular in organic cultivation, potato blight caused by the fungus phytophthora infestans can lead to significant yield, quality and storage losses. Protecting potatoes against this disease demands preventive measures, appropriate regulation strategies, and optimum spraying techniques. The latter involves an even distribution and deposition of the preventive copper contact fungicides on the stem and both sides of the leaves as well as a good penetration. Compared to conventional spraying, the newly developed underleaf spraying technique improved the coverage of the potato leaves and decreased phytophtora infection significantly.
\end{abstract}

Keywords: Application techniques $\cdot$ Biological effect $\cdot$ Leaf coverage $\cdot$ Phytophthora

\section{Materials and Methods}

In field trials carried out between 1997 and 2000, various application techniques such as flat jet nozzles with and without air assistance, injector nozzles, and an underleaf spraying system were developed and examined in the potato varieties Agria and Désirée (Fig. 1). The following parameters were investigated: labour organisation data; spray deposition and leaf coverage by means of a fluorescent tracer substance and PC-based image analysis; visual estimation of leaf infection; yield; storage, and tuber infection.

\section{Results and Discussion}

On the upper leaf side, the degree of coverage was sufficient for all variants at 23-60\%. On the lower leaf side, conventional spraying techniques reached $1-12 \%$

\footnotetext{
${ }^{*}$ Correspondence: E. Irla ${ }^{a}$

Tel.: +4152368 3359

Fax: +41523651190

E-Mail: edward irla@fat.admin.ch

aswiss Federal Research Station for Agricultural

Economics and Engineering of Taenikon (FAT)

$\mathrm{CH}-8356$ Ettenhausen

bSwiss Federal Research Station for Agroecology and Agriculture (FAL)

$\mathrm{CH}-8046$ Zürich

'Swiss Federal Research Station for Fruit-growing,

Viticulture and Horticulture (FAW)

$\mathrm{CH}-8820$ Wädenswil
}

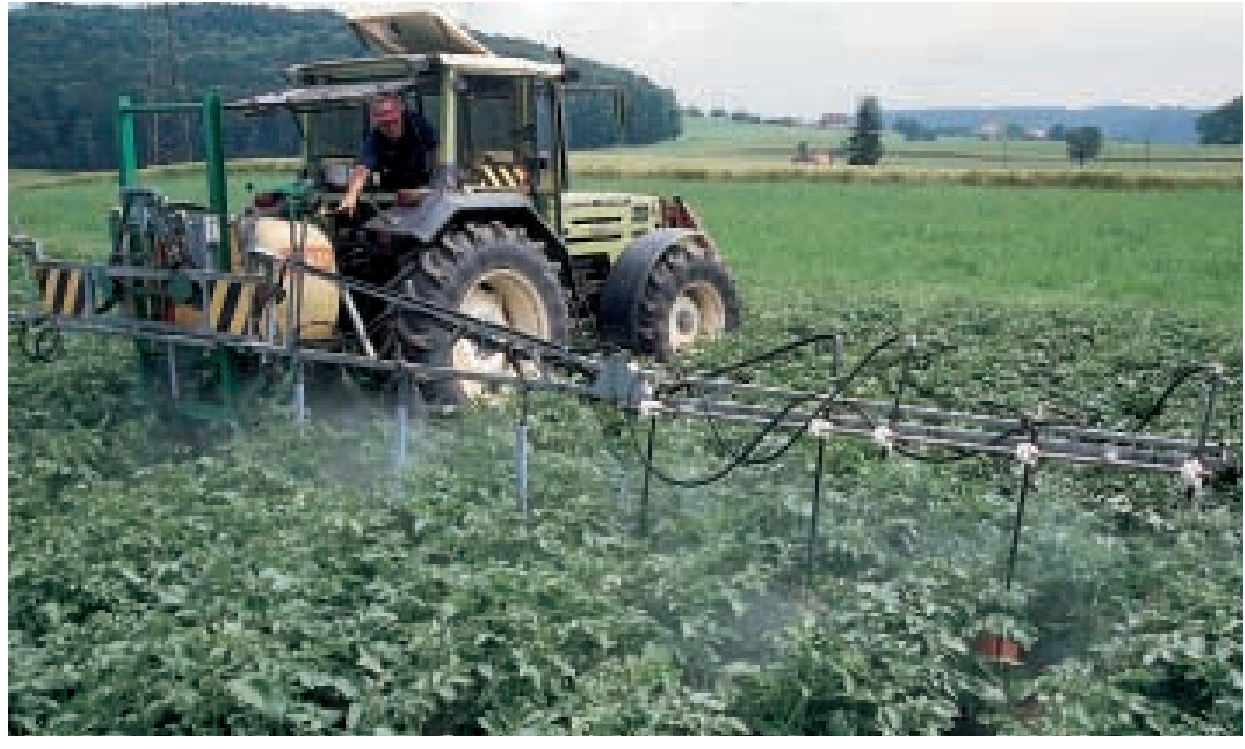

Fig. 1. An underleaf spraying system enabling the spray to be applied from above and below (system Fischer)

of coverage. Only the underleaf spraying system ensured a coverage of up to $37 \%$ on the lower leaf side (Fig. 2).

On the whole, a sufficient effect was recorded for all spraying techniques investigated. In 1999, when precipitation was extreme in May and June, extensive phytophthora infection of the non-treated plots was observed. The alternative spraying variants, in particular the underleaf variants ' $\mathrm{C}$ ' and 'D', showed a significantly better effect than the standard variant 'A' (Fig. 3).

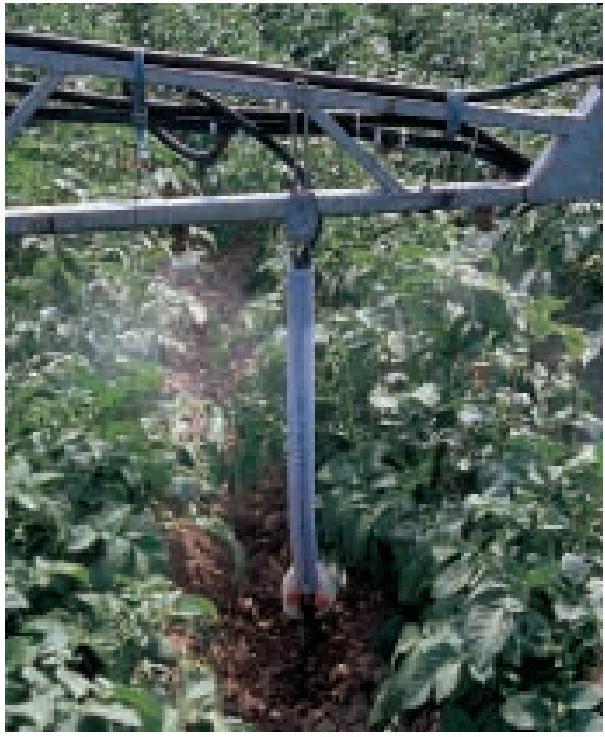



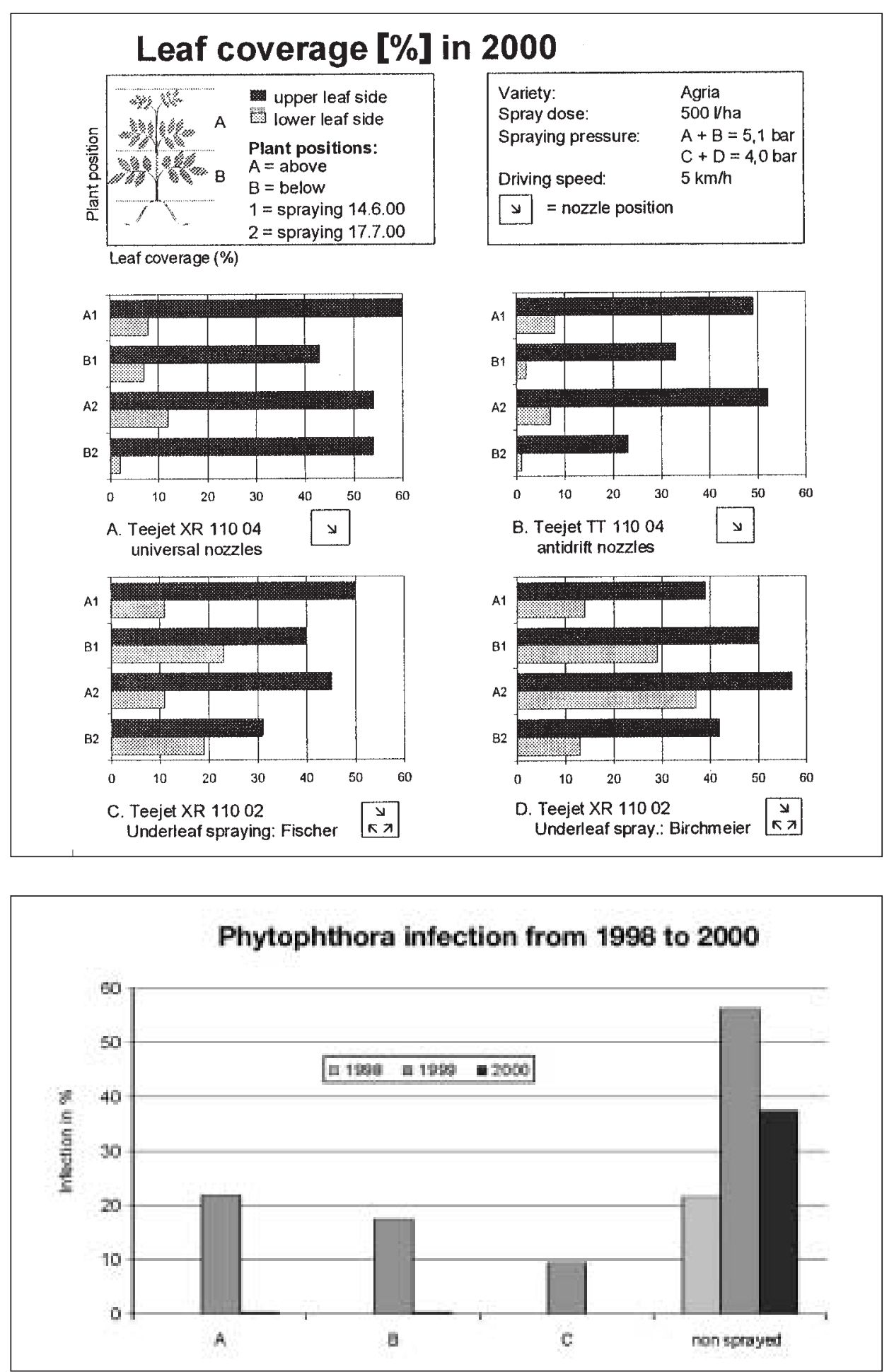

\section{Conclusions}

Excessive phytophthora infection and disease spreading could be prevented by five well-targeted sprayings

The alternative spraying techniques, in particular the underleaf spraying method, showed a considerably better result than the standard variant

A successful application technique in potatoes requires:

- $\quad$ Spray dose of 400 to 500 1/ha

- Appropriate flat jet nozzles, jet angle of 30 to $45^{\circ}$, universal and anti-drift nozzles
Fig. 2. Leaf coverage in two plant positions at two different spraying times

Fig. 3. Phytophthora infection in Agria over three years according to fungicide spraying variant

A technically sophisticated underleaf spraying technique can significantly improve spray deposition in row crops at moderate pressure and slight drift (approx. $50 \%$ spray saving). In view of using the machine in collective ownership, e.g. for dwarf beans or field vegetables, the underleaf spraying system must be adjustable to row widths of 50 to $75 \mathrm{~cm}$.

Received: May 2, 2002 